\title{
The Role of Universals in Non-Native Speakers' Learning of English: A Review Paper
}

Shahzad Ahmed

MA English Shahzad Home of Knowledge, Rawalpindi, Pakistan

DOI: $10.36348 /$ sijll.2020.v03i03.005 $\quad$ | Received: 20.01 .2020 | Accepted: 27.01 .2020 | Published: 30.03 .2020

*Corresponding author: Shahzad Ahmed

Abstract

In this paper, we will study two classes of problems in the acquisition/learning of English by non-native learners, which appear to be familiar to all language learners. We will try to determine the role played according to language universals in the acquisition of these categories. Research on the issue of the grammatical agreement has shown that there are many languages in the world, where the third person singular perfective verb is unmarked as in Semitic languages. In Arabic, for example, the third person singular masculine is the least marked: Dahab (he) went. The omission of the copula is a common problem for many speakers of different languages. In the case of EFL Arab learners, the absence of the copula is attributed either to interference with the L1, because in Arabic there is no copula in the present [1] or to a simplification strategy [2]. The fact that certain types of errors are universal let us believe deeply that universal parameters are causing such errors. The production of common errors in ESL or EFL, or in any other language, can be explained by both aspects of contrastive analysis and universal grammar.

Keywords: Acquisition, Communication, Error, Interlingual, Language, Learning, Parameter, Process, Universal.

Copyright @ 2020: This is an open-access article distributed under the terms of the Creative Commons Attribution license which permits unrestricted use, distribution, and reproduction in any medium for non-commercial use (NonCommercial, or CC-BY-NC) provided the original author and source are credited.

\section{INTRODUCTION}

Second language (L2), in a broad sense, is a language learned or acquired after the native language. The term has a narrow sense when it contrasts to the term "foreign language"( $F L)$, in which second language "functions as a recognized means of communication among members who speak some other languages as their mother tongue," and the foreign language "plays no major role in the community and is primarily learned only in the classroom" [3]. So, L1 is assumed to be one which is acquired during early childhood- starting before the age of about 3 years [4]. According to Eastman, "a foreign language is used in a speech community different from the one where the learner lives, whereas a second language is used in a speech community in which the learner already uses his first language" [5]. However, According to Houmanfar, Hayes, and Herbst [6], the first and second languages are interrelated, and the history of the first language is a participatory factor in the acquisition of the second language (L2) and its maintenance. L1 and L2 acquisition generally refers to one of the following categories [7]: the first category concerns cognitive differences where adults have already learned the first language and have better-developed analytic abilities than children. They also have metalinguistic knowledge that children lack. Whereas effective differences, the second category, presents adults as motivated to learn in a way that does not apply in the case of children acquiring an L1. Adults also experience acculturation to a greater or lesser degree in the course of L2 acquisition, whereas child language acquisition is integral to the process of enculturation, in which one becomes a member of a cultural group.

Furthermore, the third category, which is biological differences, argues that after a critical period, which ends approximately at the age of 12 , the child loses the biological attributes that allow him to learn the first language. Moreover, the L1 acquisition is subject to a critical period. In connection with the issue of learning a second language and learning a foreign language, the work of Krashen [8] distinguishes between "acquisition" and "learning." He said the acquisition is a subconscious process in which the learner uses the target language for "authentic" communication, while learning is a conscious process in which the learner consciously focuses on the linguistic form and the formal characteristics of the target language. Krashen uses this distinction to explain his theory of second language acquisition. Other researchers, however, argue that the two terms of 
"acquisition" and "learning" are used ambiguously and are devoid of logic and practical support [9]. According to Richards [10], Krashen's distinction between acquisition and learning is based on "anecdotal" evidence. Thus, the rules of spelling and punctuation are learned consciously and eventually become automatic and subconscious. This concerns both SLL and FLL.

Researchers on EFL learning show that learners use the same strategies as children acquiring their native language and as second language learners. It was also shown that certain errors committed by native speakers and learners of a second language are like those of EFL learners. If the theory L1 = L2 hypothesis is based on the similarity of mistakes and learning strategies, it is logical to think that learning a foreign language is not different from learning a second language. It may be true that EFL learners begin to learn the language in a conscious way, but this process becomes gradually subconscious. The question at this level is not to know whether English is taught as a foreign or a second language, but whether similarities between the acquisition of L1 and that of L2 are restricted to learning the second language. The answer to this question is negative, as demonstrated by Dulay and Burt, Richards. Moreover, researches on syntactic deviations in the productions of non-native speakers of the language are in their majority understandable. This finding allows us to go beyond the issue of similarities between L1 and L2 and the intelligibility of the production of the non-native speaker in the field of language universals. According to Gass [11], we need to know more about the idiosyncrasies and the universals of language acquisition as the universal strategies and processes of the $\mathrm{L} 1=\mathrm{L} 2$ hypothesis was based on paralinguistic factors. Several proposals have been elaborated within the Principles and Parameters Theory, particularly [12, 13] and Optimality Theory that aim to incorporate typological universals, at least exceptionless ones, into Universal Grammar. Finally, Leaver [14] acknowledge that the language learning experience differ and depend on whether it is the L1 or L2, but it is not always clear which elements of the acquisition process are innate or extrinsic

\section{Universals of $L 2$ acquisition}

Jakobson [15] was the first to define and develop the linguistic approach to language acquisition even though his research is limited to its phonological acquisition. He believes that language acquisition is subject to universal regularities that can be described in a linguistic framework. The term "universal" means two things, the type of language and language acquisition. Typological universals determine the restrictions on a structure of rules in all-natural languages. Universals of acquisition are patterns that appear in all situations in which languages are learned. According to Chomsky [16], the main task of linguistics is to represent the universals of language. The relationship between first language acquisition and language universals has been a focus in the search for language universals. According to Chomsky [17], universals are, in the language field, necessary conditions for acquiring a first language. In the eighties, researchers were interested in studying the relationship between second language acquisition and language universals [18]. According to Gass [11], data from the acquisition of the second language give a possibility of investigation and verification of language universals. Research on language acquisition and language universals knows two approaches: a) Chomsky's approach, which considers the universal properties as innate. Consequently, children are capable of acquiring a language in minimal time;

b) The universal approach, proposed by Greenberg [19], focuses on finding the principles that underlie regularities according to which languages vary, and the constraints and principles underlying these variations. According to Chomsky, universal principles vary subtly from one language to another, which resulted in the introduction of the concept of "parametric variation." The main idea is that only a limited number of parameters are associated with a particular principle. Thus, the specific differences of language in many cases are reducible to differences in the options that universal grammar makes it valid. Thomas [20] proposes the following definition: "universal grammar consists of the linguistic properties shared by all languages". In the following, we will study two classes of problems in the acquisition of English by non-native learners who appear to be common to all language learners. We will try to determine the role played by language universals in the acquisition of these categories.

\section{The Mark of the Third Person Singular in the Simple Present Tense}

The omission of "s" in the third person singular in the simple present tense is a common phenomenon to all learners of ESL/EFL, children, or adults. The origin of the interference in this category, according to researchers, varies from one language to another. Some researches on EFL Arab learners attribute, for example, the omission of the "s" to interference with the mother tongue [21-25]. Why is this category problematic for all EFL learners? From a broader perspective, the obvious question is: what explanation can we give to the universal production of a particular error in L2 learning? Before answering these questions, we will study some data produced by different language learners. Richards [10] analyzed the errors produced by children learning English as a second language.

Their native language was from different origins (Spanish, Japanese, Chinese, etc.).
1. He Always Talks About
2. He comes from India
3. She speaks German 
According to Richards, these errors are due to a simplification strategy used by children. Foley [26] studied language development in pre-scholars in Singapore. The native languages spoken by these children were: Malay, Hindi, Chinese, and Tamil. The following are examples of structures produced by these children:

4. Who says no light

5. My mother tells me

6. Then the teacher says Keep the toy

These deviations are standard in all children despite their L1. Richards, after analyzing the texts written in English by adult learners from Thailand, considered the omission of the morpheme "s" in the third person singular as a problematic area:

7. Everyone wants to live in a dormitory

According to Richards, this problem is not attributed to an interference with L1 but an intralingual source. In the same way, Smith [27] reported similar errors produced by students from New Guinea that have L1 as Pidgin and formal learning English at the university as a second language. The following are examples of mistakes made by these students:
8. It Stretch 8.54
9. Write a sentence which classifies The Method
10. I hear that the badly need a postmaster
11. When he visits The Factory

Most researchers have explained this class of deviations as an intralingual influence. However, is this category problematic only for non-native speakers of English? Obviously, no! Brown [28], studying the acquisition of English by three children, noted similar errors.

12. Mammy use it

13. Cromer comes on Wednesday

14. He wants some milk

Simplification seems to be a possible explanation for such errors, but in this case, the most plausible explanation is that the omission of "s" is due to the non-existence of SVO in the grammar of the child. However, this conclusion does not answer the question: why is this phenomenon dangerous even for speakers of languages that have a high flexion and for which we expect a positive transfer?

Greenberg [29] made a suggestion here that provides various forms to grammatical agreements:

- The agreement is a universal form (although optional in some languages) which performs a defined operation by a restricted set of characteristics, e.g., gender, number and person. According to Haspelmath [30], the above-stated criterion is valid only for the inflectional categories of agreement, "because the syntactic relation of the agreement is their sole raison d'être."
- The mark of the third person singular is a universal principle implemented on the syntax of the language.

- The masculine singular is the unmarked characteristic of gender and number.

Research on the issue of the grammatical agreement has shown that there are many languages in the world where the third person singular perfective verb is unmarked as in Semitic languages. In Arabic, for example, the third person singular masculine is the least marked:
15. dahaba (he) Went
16. dahabnaa ---------we Went
17. dahabat ------------she went
18. dahabna-----------they (f) went
19. dahabtu ----------I went
20. dahabuu-----------they $(\mathrm{m})$ went
21. dahabta -----------you went
22. dahabtum --------you (pl.) went The same case in Hebrew:
23. yashavant--------- (he) sat
24. yushevit------------you sat
25. yashvah------------she sat
26. yashvuu ------------they sat

As we can see in (15) and (23), Arabic and Hebrew have, respectively, a and 0 (zero) marks for the third person singular masculine. Similar cases are found in other languages such as Thai [31]. Even in Spanish, the third person singular (imperfective verb) is the least marked, as shown in the following examples:

27. coma -----------o / she eats
28. comas --------you Eat
30. comanos-------we Eat
31. comes-----------you eat

Theoretically, it seems clear that the mark of the third person singular in the simple present tense is a specific phenomenon to English. Learners usually have a universal parameter that makes them consider the third-person singular as unmarked.

\section{Omission of the copula}

The following sentences are examples of structures where the copula has been omitted from the production of ESL/EFL learners from different origins (ESL/EFL learners: Arabic, Japanese, Chinese, etc [10]:

1) Mary lovely

2) I afraid late you go to church

3) He not here. No one here (ESL learners: Malay, Chinese, Hindu, Tamil [26]:

4) When coming Jane

5) What she is doing

6) I late. So sorry

7) The expensive dress. Year not buy

8) He born in England

9) He disgusted 
10) She very naughty (Moroccan learners) [32]:

11) There no food

12) The man there

13) The girl very beautiful

(Even if, nowadays, Malaysian English is being acknowledged as a variety of English (i.e. Manglish) which is colloquial, so the same as a native English speaker speaking in an informal situation, there's a tendency of shortening the phrase by omitting the auxiliary).

The omission of the copula is a common problem to many speakers of different languages. In some studies, devoted to second language acquisition, researchers consistently report that learners of ESL / EFL omit the copula. In the case of EFL Arab learners, the absence of the copula is attributed either to interference with the L1, because in Arabic there is no copula [1] or to a simplification strategy [3].

According to Richards [33] and Foley [26], ESL / EFL Chinese and Thai learners omit the copula because of interference from L1. The lack of a consensus among researchers about the origin of the copula, either intra-lingual or interlingual, and the fact that it may be common to all L2 learners, show that there is a common universal factor which governs the production of such an error. Simplification seems to be a reasonable explanation since the copula is in the grammatical system of English children. However, this finding does not clearly answer the question: why is copula omitted despite the original language, even if L1 has a copula?

Chomsky [17] explains that elements which are grammatically and semantically meaningless are universally omitted. This means that there is an inserted element in the universal grammar (that is, all meaningless elements have no role and then are omitted). However, such a vacuum is filled later in the acquisition, as a special phenomenon of language. This clearly explains the universal omission of the copula in the production of English learners. In the case of nominal sentences, the copula does not contribute in a pragmatic and semantic meaning of the sentence. In the case where the copula is an auxiliary, tense and aspect are expressed by the morphology of the main verb, for example a word with "-ing" form. The suffix "-ing" expresses tense, and thus the copula is considered as an empty element. Therefore, the copula is omitted.

According to Guntermann [34], the fact that adult speakers of English omit the copula in learning Spanish is a further proof of the existence of this universal parameter. Consider the examples of Guntermann:

14) Mi madre a pajaro

15) Ellos divociados

\section{6) Ella no mi novia ahora}

The origin of such errors is contrary to what was predicted. This remains true for Spanish and French adult speakers learning English, because Spanish and French have the copula in their grammatical systems. It has often been advanced for the acquisition and learning of the second language, the similarities between languages are somewhat problematic and induce a positive transfer. The fact that learners make mistakes is itself a clear indication that they have recourse to universal grammar.

The universal of Chomsky [17] is used to explain the omission of lexical subjects in Pro-drop languages and the role played by the Pro-drop parameter in the grammars of children [35]. Data on children learning English used by Hyams show that there is no place where children are likely to omit the subject when the main verb is an auxiliary. For example: "Read book bear", "want to get it", "rid truck", "See under there". The reason is that in ProDrop languages (Arabic, Bantu, Italian, Spanish, etc.) characteristics of the agreement relate to the verb, which is not the case in English. This supports the idea that the omission of the copula is the result of a universal parameter.

So, this universal parameter explains the absence of the subject in EFL learners with different mother tongues. Consider the following sentences from Malay and Chinese learners [26]:

17) Because the annual cannot pass university and college entrance examination

18) Can play afterwards

19) Because inside pocket could and these examples from Moroccan learners [32].

20) The first time when reached here

21) When in our university came

22) After will come back

These errors are explained by L1interference, according to the Pro-Drop parameter. Thus, the explanation put forward by Kambal [36] on the lack of subject in these examples, which would be a performance error is inadequate. Data acquisition and second language learning support the idea that learners, in the process of learning a new language, do not rely on the grammars of the learned language, but instead, they rely on universal parameters.

\section{CONCLUSION}

What is the relationship between acquisition and learning a second language and linguistic theory? It has often been argued that applied linguistics has no impact on theoretical linguistics. However, it has been shown through research on language acquisition and language universals that such an idea is not valid. Even if applied linguistics may not have direct impact on theoretical linguistics, it provides the remarks which 
linguistic theories need and helps validate and explain the abstract concepts of language. Indeed, the ultimate goal of linguistic theory is to explain in a better way the language development and acquisition.

The relationship between the results of studies on learners of ESL and EFL, in general, and language universals actually shows that universals have an important role to play in the acquisition and learning of languages despite the context in which the new language is learned, either a foreign language or a second language. Research has shown that second language learners have similar problems as learners of a mother tongue, the L2 learners eventually acquire reasonable competence in their L2. The fact that certain types of errors are universal let believe deeply that there are universal parameters causing such errors, in other words, the learner simply selects the parameters that are appropriate, given the input [37]. Production of common errors in ESL or EFL, or in any other language, can be explained by both aspects of contrastive analysis and universal grammar.

\section{REFERENCES}

1. Scott, M. S., \& Tucker, G. R. (1974). Error analysis and English language strategies of Arab students. In Language learning, 24(3), 66-97.

2. Dulay, H. C., \& Burt M. K. (1974). Error analysis: Perspectives on second language acquisition, edited by Jack C. Richards. Longman Group Limited. London.

3. Ellis, R. (1994). The Study of Second Language Acquisition. Oxford University Press.

4. Sinha, A., Banerjee, N., Sinha, A., \& Shastri, R. K. (2009). Interference of first language in the acquisition of second language. Journal of Psychology and counseling, 1(7), 117-122.

5. Eastman, C. M. (1983). Language Planning: An introduction. Chandler and Sharp Publishers Inc. San Fransisco.

6. Houmanfar, R., Hayes, L. J., \& Herbst, S. A. (2005). An Analog study of first language dominance and interference over second language. Anal Verbal Behav, 21(1), 75-9

7. Myers, B., Hudson, S. E., \& Pausch, R. (2000). Past, present, and future of user interface software tools. ACM Transactions on Computer-Human Interaction (TOCHI), 7(1), 3-28.

8. Krashen, S. D. (1982). Second language acquisition and second language learning. Oxford: Pergamon Press Ltd.

9. Gregg, K. (1984). Common errors in learning English, Rowley, MA: Newbury House. Krashen's Monitor and Occam's Razor. Applied Linguistics, 5(2), 79- 100.

10. Richards, J. C. (1985). Error analysis, interlanguage, and second language acquisition: A review in Richards, J. C. (ed.) The context of language teaching. Cambridge: Cambridge University Press.
11. Gass, S. (1979). Language transfer and universal grammatical relations. Language Learning, 27, 327-344.

12. Baker, M. C. (2001). The Atoms of Language. New York: Basic Books.

13. Baker, M. C., \& McCloskey, J. (2005). On the Relationship of Typology to Theoretical Syntax. Paper from theLSA Symposium on Typology in the U.S. Downloadable at http://www.rci.rutgers.edu/mabaker/papers.html.

14. Leaver, B. L., Ehrman, M., \& Shekhtman, B. (2005). Achieving Success in Second Language Acquisition. Cambridge: Cambridge University Press.

15. Jakobson, R. (1956). Two aspects of language and two types of aphasic disturbances. In Jakobson, R., \& Halle, M. 1956. Fundamentals of language. The Hague: Mouton.

16. Chomsky, N. (1956). Three models for the description of language in I.R.E. Transactions on information theory, 2, 113-124.

17. Chomsky, N. (1981). Lectures on Government Binding, Foris. Dordrecht.

18. Fisiak, J., Grzegorek, M., \& Zabrocki, T. (1978). An introductory English-Plish contrastive grammar. Warszawa: Panstwowe Wydawnic two Naukowe.

19. Greenberg, J. H. (1978). Universals of human language: Method and Theory. Stanford University Press, Volume 1. Georges, H.V. 1972.

20. Thomas, M. (2004). Universal Grammar in second language acquisition. London and New York: Routledge.

21. Duskova, L. (1969). On sources of Errors in foreign Language Learning, IRAL, 7, 11-36.

22. Dulay, H., \& Burt, M. (1978). Some remarks on creativity in language acquisition. Second language acquisition research: Issues and implications, 65-89.

23. George, A. L., \& Smoke, R. (1974). Deterrence in American foreign policy: Theory and practice. Columbia University Press.

24. Mukattash, L. (1978). A pilot project in common grammatical errors in Jordanian English. In Interlanguage studies bulletin, 3(2), 250-291.

25. Sharma, V. A. (1981). Syntactic errors as indices of developing language proficiency in Arabic speakers' writing English at the intermediate and advanced levels of English as a second language. University of Indiana. Bloomington.

26. Foley, J. (1984). A study of the development of language among preschool children in Singapore with particular reference to English in On TESOL 84, edited by Penny Larson et al., Universityof Georgetown, Washington D.C.

27. Smithies, M., \& Smithies, S. H. (1981). Errors in Papua New Guinea written English at the tertiary level. In RELC Journal, 2(1), 10-35.

28. Brown, R. (1973). A First Language: The early stages, Allen \& Unwin. London. 
29. Greenberg, M. S., \& Frisch, D. M. (1972). Effect of intentionality on willingness to reciprocate a favor. Journal of Experimental Social Psychology, 8(2), 99-111.

30. Haspelmath, M. (2002). Understanding Morphology. London: Arnold.

31. Richards, J. C. (1971). "Error analysis and second language strategies". English Language Teaching Journal, 25, 204-219.

32. Mazari, A. (2006). Analyse d'erreurs dans l'apprentissage de la L2: l'exemple arabe-anglais. Paris X-Nanterre.

33. Richards, J. C. (1974). Error Analysis London: Longman.

34. Guntermann, C. G. (1977). An investigation of the frequency. Comprehensibility and evaluation effects of errors in Spanish made by Englishspeaking learners of ElSalvado. University of Ohio.

35. Hyams, N. (1983). "The Pro-Drop parameter in child grammars" in West coast conference on foreign language teaching, edited by Hakan Ringborn. Publications: The research Institute of the Abo Akademi Foundation.

36. Kambal, M. A. A. (1981). An Analysis of Khartoum University Students'composition Errors with Implications for Remedial English in the Context of Arabicization.

37. Jackendoff, R. (2002). Foundations of Language. Oxford: Oxford University Press. 